\title{
Giant calvarial haemangioma with classical radiological features
}

\author{
Surya Nandan Prasad, ${ }_{1}^{1}$ Upendra Chaudhary, ${ }^{2}$ Madhuri Kumari, ${ }^{2}$ Hira Lal ${ }^{1}$
}

${ }^{1}$ Department of Radiodiagnosis, Sanjay Gandhi Postgraduate Institute of Medical Sciences, Lucknow, India

${ }^{2}$ Department of Radiodiagnosis, All India Institute of Medical Sciences, New Delhi, India

\section{Correspondence to}

Dr Hira Lal,

hirala12007@yahoo.co.in

Accepted 22 October 2017
CrossMark

\section{To cite: Prasad SN,} Chaudhary U, Kumari M, et al. BMJ Case Rep Published Online First: [please include Day Month Year]. doi:10.1136/bcr-2017 223029

\section{DESCRIPTION}

A 12-year-old girl presented with a large painless hard swelling in the left parietal region, gradually increasing in size for 6 years. No complaint of headache or visual disturbance was present. Radiographs showed a large expansile lytic lesion with prominent bony trabeculae radiating centrifugally from the centre of the mass. On CT scan, the lytic area showed areas of rarefaction traversed by radiating bony spicules. On MRI, the lesion was isointense to hyperintense on T1-weighted images (T1WI), hyperintense on T2WI, indenting over underlying brain parenchyma, causing mass effect and midline shift. Avid enhancement was noted on postcontrast scans (figure 1). Based on typical clinical presentation and classical radiological findings, a diagnosis of giant calvarial haemangioma was made.

Calvarial haemangiomas are benign vascular tumours with a propensity to involve the diploe and outer table, sparing inner table of skull. ${ }^{1}$ Overall calvarial haemangiomas account for $0.2 \%$ of all bone tumours. ${ }^{1-3}$ Giant calvarial haemangiomas are even rarer. ${ }^{2}$ They are approximately three times more common in women with peak incidence in second to fourth decades. ${ }^{1-3}$

On skull radiographs, giant calvarial haemangiomas present as expansile lytic intradiploic mass with radiating bony trabeculae giving a classical 'sunray pattern'

\section{Learning points}

- Giant calvarial haemangiomas are benign vascular tumours, involving diploe and outer table and sparing inner table of skull.

- Classical 'sunray appearance' on tangential radiographs and typical 'sunburst pattern' on CT bone window scans are highly suggestive of calvarial haemangioma.

- En bloc surgical excision of the mass results in cure. Preoperative embolisation can be considered to reduce vascularity of the mass.

on tangential views. ${ }^{12}$ CT scan shows multiple bony spicules radiating from the centre to periphery of the lesion described as 'sunburst appearance'. ${ }^{23}$ On MRI, they are well-circumscribed masses, hyperintense on both T1WI and T2WI and show intense postcontrast enhancement. Complete surgical resection is the treatment of choice. ${ }^{23}$ Simple curettage may result in recurrence. Preoperative embolisation may be considered before surgery to reduce vascularity of the mass. ${ }^{3}$

Contributors SNP and HL conceived the manuscript. SNP prepared the manuscript. UC and MK collected the images and also helped in manuscript preparation. HL and SNP edited the manuscript. The final manuscript was read and approved by all the authors.

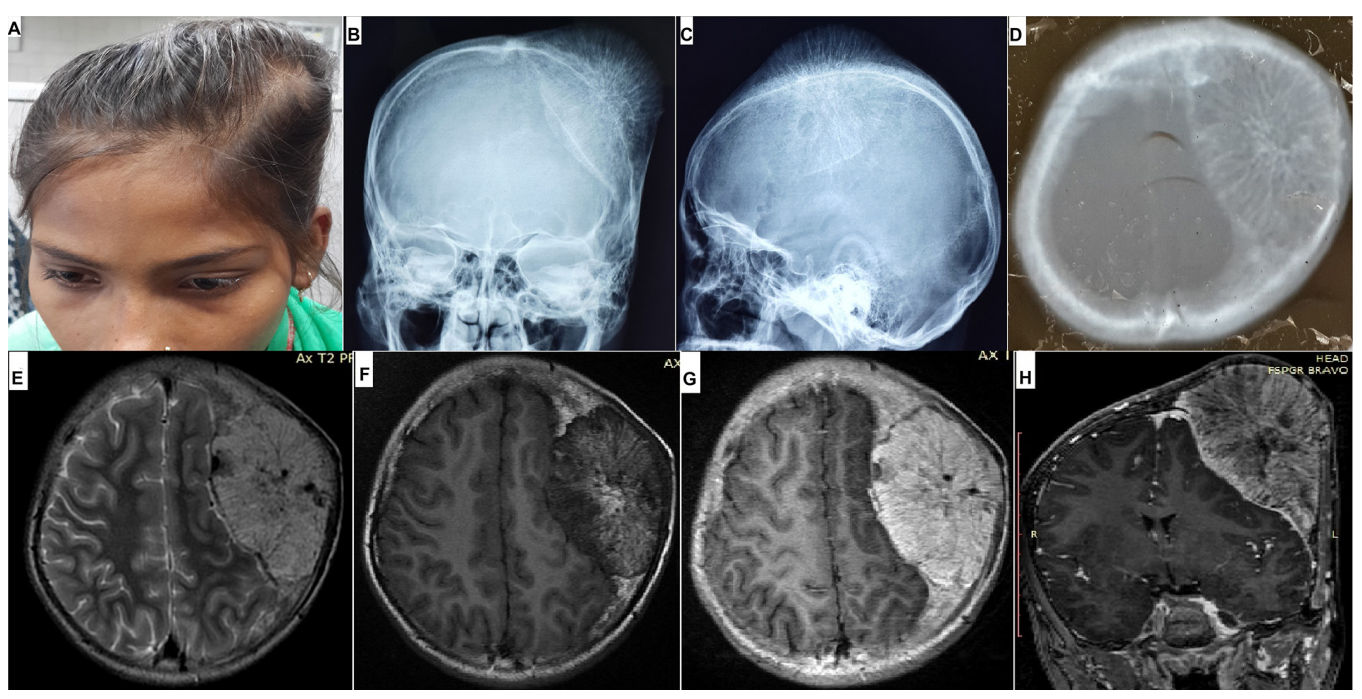

Figure 1 (A) Clinical photograph showing large left parietal swelling. (B and C) Skull radiograph in frontal and lateral projections showing lytic lesion with centrifugally radiating bony trabeculae giving typical 'Sunray appearance'. (D) CT scan in bone window showing the lytic area traversed by prominent radiating bony spicules giving it the classical 'sunburst appearance'. (E) MRI (T2-weighted image) showing well-defined hyperintense mass. Precontrast (F) and postcontrast (G) T1WI showing intense postcontrast enhancement of the mass. (H) Postcontrast coronal image shows large enhancing lesion indenting over the brain parenchyma causing mass effect and midline shift. 
Competing interests None declared.

Patient consent Consent obtained.

Provenance and peer review Not commissioned; externally peer reviewed.

(c) BMJ Publishing Group Ltd (unless otherwise stated in the text of the article) 2017. All rights reserved. No commercial use is permitted unless otherwise expressly granted.

\section{REFERENCES}

1 Verma SK, Singh PK, Garg K, et al. Giant calvarial cavernous hemangioma. J Pediatr Neurosci 2015;10:41.

2 Mohindra S, Kapoor A, Mitra S, et al. Giant primary calvarial hemangioma over torcula: Radiological features and operative nuances. Surg Neurol Int 2016:7:440.

3 Colas L, Caron S, Cotten A. Skull vault lesions: a review. AJR Am J Roentgenol 2015;205:840-7.

Copyright 2017 BMJ Publishing Group. All rights reserved. For permission to reuse any of this content visit http://group.bmj.com/group/rights-licensing/permissions.

BMJ Case Report Fellows may re-use this article for personal use and teaching without any further permission.

Become a Fellow of BMJ Case Reports today and you can:

- Submit as many cases as you like

- Enjoy fast sympathetic peer review and rapid publication of accepted articles

- Access all the published articles

Re-use any of the published material for personal use and teaching without further permission

For information on Institutional Fellowships contact consortiasales@bmjgroup.com

Visit casereports.bmj.com for more articles like this and to become a Fellow 